\title{
Values clarification: Essential for leadership learning
}

\author{
Mackenzie R. Fritz \\ Associate Director of REHS for Academic Initiatives, Student Behavior, and Leadership \\ Michigan State University
}

Kathy L. Guthrie

Associate Professor, Higher Education

Florida State University

\begin{abstract}
Values clarification is a dynamic process in which people come to understand what they individually view as important in their lives by placing a name or label to what one values. This process commonly occurs during the traditional college years and is a critical component of leadership education. This qualitative study examined how junior-level undergraduate students clarify their values in the environment of a series of leadership courses at a large, Research I institution in the southeastern United States. Two major themes emerged including course curriculum and structure, and leadership learning environment. Findings from this research helped to explain the experience of how junior-level students clarify their values in their collegiate experience and inform the practice of leadership curriculum development in colleges and universities.
\end{abstract}

\section{Introduction}

Understanding what individuals view as important to their lives by placing a name or label on it provides language to what one values. This clarification often happens during traditional college years and is a critical component of leadership education. For students to learn how to be a positive leader, they need to clarify their values. The purpose of this study was to contribute to a better understanding of how undergraduate students clarify their values in college. The research questions addressed the phenomenon of values clarification through the undergraduate experience, specifically in leadership courses for junior-level students. Specific research questions include "Do students clarify their values through leaderships courses?" and "What most influenced the students' values clarification process within leadership courses?" Both the purpose of the study and the research questions were based on arguments concerning the underlying problem: how students understand what they value through college.

\section{Values Clarification in Leadership Education}

In creating effective leadership development programs, Connaughton, Lawrence, and Ruben (2003) assert that leadership development is a fundamental responsibility of the modern college and university. Osteen and Coburn agree stating, "successful collegiate leadership programs are embedded in and aligned with the following four contextual layers: higher 
education's purpose, institutional mission, administrative support, and collaborative environment" (2012, p. 5). Connaughton et al. (2003) cited nine foundations on which the pedagogy of leadership is founded. The foundations are complex, other-oriented, interactive and dynamic, contextual, a science and an art, enacted through communication, increasingly mediated and virtual in nature, emergent, and able to be learned and taught (Connaughton et al., 2003). The authors emphasized the importance of an engaging, interactive classroom where reflection is encouraged. To educate leaders, it is critical to allow students to apply the leadership theory they have learned in the classroom to their leadership practice (Connaughton et al., 2003). Schwartz (2015) states that leadership education in a group is particularly powerful. Much of ethical leadership work is grounded in social learning theory and aligns with the collaborative nature of leadership learning environments, making both in and out of the classroom group work critical. Additionally, Guthrie and Thompson (2010) assert that "leadership education be comprised of a balanced mix of three elements: formal education in theories and principles of leadership, practical experience, and reflection on experiences in light of formal education" (p. 50).

In order to maximize the benefit of curricular leadership development programs, educators should continue to clarify personal values in college students and integrate values development into the curriculum. The current paradigms of leadership development necessitate the development of both personal and social values in leaders (Cress, Astin, Zimmerman-Oster, \& Burkhardt, 2001). The Council for the Advancement of Standards in Higher Education suggested "leadership development involves engaging with learning opportunities in one's own environment... to build one's capacity or efficacy to engage in leadership. This developmental approach entails moving from simple to more complex dimensions of growth" (Komives, Longerbeam, Owen, Mainella, \& Osteen, 2006, p. 402). Northouse (2010) agreed emphasizing, "it is crucial to state that leadership involves values, and one cannot be a leader without being aware of and concerned about one's own values" (p. 395, emphasis in original). Thompson (1991) echoed the importance of teaching moral responsibility, particularly to our leaders, encouraging "any institution which is concerned with the moral imperatives must teach responsibility, for responsibility is the other side of morality" (p. 4). However, a first step to understanding values is a path to values clarification put it into educational practice.

Value. Schwartz and Bilsky (1987) conducted a literature review and found five features common to values definitions. They state values are "(a) concepts or beliefs, (b) about desirable end states or behaviors, (c) that transcend specific situations, (d) guide selection or evaluation of behavior and events, and (e) are ordered by relative importance" (Schwartz \& Bilsky, 1987, p. 551). Schwartz (1994) later defines values as "a belief pertaining to desirable end states or modes of conduct that transcends specific situations, guides selection or evaluation of behavior, people, and events, and is ordered by importance relative to other values to form a system of value priorities" (p. 20). Whereas the Ethics Resource Center defines values as, "core beliefs that guide and motivate attitudes and actions" $(2009$, p. 1). In taking all of these definitions into consideration, we have defined values for this study as a set of chosen, strongly held beliefs that form one's philosophy and are expressed through feelings, behaviors, and decisions. Values serve as general guides to behavior and choices. One's chosen values emphasize the standards one tries to endorse and maintain throughout one's life. 
Values Clarification. There are many different definitions of values clarification in the literature (Attarian, 1996; Boone, 2003; Kirschenbaum, 1976; Kirschenbaum, Harmin, Howe, \& Simon, 1977; Mosconi \& Emmett, 2003; Purpel, 1991; Simon \& deSherbinin, 1975; Simon, Howe, \& Kirschenbaum, 1978). From these, we synthesized a definition of values clarification for this study. Values clarification is an on-going process of the development of defining what one values (what one believes to be most important and what one cares for most), and how one acts on those values in daily life. Values clarification is the process of defining one's values. By clarifying our values, it helps to guide us in our daily activities and helps to align what we say with what we do. After someone has clarified his or her values, they should be able to quickly name the values held most dear.

Kirschenbaum's definition of values clarification is "an approach that utilizes questions and activities designed to teach the valuing process and to help people skillfully apply the valuing processes to value-rich areas in their lives" (Kirschenbaum, 1976, p. 103-4). However, Kirschenbaum did not assert that values clarification will be the one true answer for humankind, as it does not provide all of the answers. Yet, Kirschenbaum's work does explain a process for valuing. The author posited if people engage in this process, their lives will have more positive value and they will become constructive global citizens (Kirschenbaum, 1976).

Values Clarification and Morality. Values clarification does not have a moral connotation; rather, values clarification is about understanding what is viewed individually as important. "It is the goal of values clarification to unmask what is important to the individual... Values clarification, therefore, focuses on what is the right decision about a person's feelings about life or about a particular idea" (Boone, 2003, p. 1). When it comes to values clarification, there is no absolute truth. Rather, it is about understanding and championing what one believes to be true (Mosconi \& Emmett, 2003). Therefore, when in the classroom, Kirschenbaum advocated for assisting students in developing their own values, rather than the instructor imposing his or her values on the students (2000). However, there was criticism to the values clarification approach. It was criticized for what was perceived as the promotion of moral relativism (Smith, 2013).

Kirschenbaum (2000) argued against critics who claim the values clarification process is devoid of morals and is egocentric. He claimed we showcase our values (specifically in the classroom), and students see the modeling of the behavior. The process of values clarification provides a means to teach students a set of skills that will be with them always; rather than our values that will only be with students when we are with them. Therefore, it is not devoid of values, but devoid of judgment and a perceived morality.

In contrast to the moral education prescribed by some of their contemporaries (and in agreement with Kirschenbaum's ideas), Simon and deSherbinin (1975) outlined why values clarification does not address moral issues in its approach. "Moralizing offers the illusion of looking like the right way to go, but its whole focus - trying to shape and manipulate people in to accepting a given set of values - is doomed to failure" (Simon \& deSherbinin, 1975, p. 682). If a student has not been educated on how to formulate his or her own values, other people may influence his or her values. For example, "if a student has not been taught to examine and weigh 
his own values, he is prey to the next fast-talking moralizer who comes down the road. The next one might, in fact, be hustling drugs" (Simon \& deSherbinin, 1975, p. 682).

Values Clarifying Exercises. One method employed by educators to assist students in clarifying their values, is the use of Values Clarification exercises. The process begins with recognition of a value problem, such as apathy (Kirschenbaum et al., 1977). Then the intervention is conducted. This intervention's purpose is to change the state of affairs (confusion and conflict) within the person. In order to do so, the process involves a form of questioning through activities (or strategies). The questioning includes many different content areas, all of which help people to determine answers to value-laden problems in their lives (Kirschenbaum et al., 1977). These values clarification exercises are often designed to help people become more aware of their own values (Mosconi \& Emmett, 2003).

Values clarification exercises contain four main elements. The first includes choosing a value-laden matter "such as an issue related to friendship, family, health, work, love, sex, drugs, leisure times, personal tastes, or politics" (Kirschenbaum, 2000, p. 5). This topic can be chosen by the educator or by the participants. Next, the facilitator raises a question, or leads an activity, "sometimes known as a values clarification 'strategy,' to help the participant(s) think, read, write, and talk about the topic" (Kirschenbaum, 2000, p. 5). During the third stage, the leader makes sure all perspectives are treated with deference, therefore creating a safe space for conversation. In the fourth element, the organizer helps the members to use valuing processes or valuing skills to rectify the problem at hand. The fourth element involves "understanding what one prizes and cherishes, publicly affirming one's values in appropriate ways, examining alternative viewpoints, considering the consequences of various choices in a thoughtful manner, making a choice free from undue peer or authority pressure, and acting on ones beliefs" (Kirschenbaum, 2000, p. 6). The specific research questions for this study include "Do students clarify their values through leaderships courses?" and "What most influenced the students' values clarification process within leadership courses?" The study context for this study is specifically leadership courses. More specific information about this context follows.

\section{Study Context: Leadership Certificate}

The leadership courses in this study are a part of a Certificate in Leadership Studies at a large, research-intensive, public institution in the Southeast. The Leadership Certificate provides an environment designed to foster student development and is based on a seamless learning model, where students engage in learning both inside of and outside of the classroom environment, created on a foundation of community building, education and reflection (Guthrie \& Bovio, 2014). The Certificate is interdisciplinary and multidisciplinary, where students of various majors and experiences interact. The student population enrolled in the Certificate is diverse (in regard to gender, age, background, major of study, year in school, etc.). While enrolled in the Certificate, students engage in multiple collaborative projects and are encouraged to engage in dialogue during class time.

The Certificate requires five core courses focused on knowledge, skills, and values of leadership within specific contexts. LDR 2101: Leadership Theory and Practice (Theory)focuses on providing a strong foundation of general leadership theory and the individual in the leadership 
process. LDR 2162: Leadership in Groups and Communities (Groups) focuses on leadership in the context of groups and communities. Change and transition theories are explored in LDR 3215: Leadership and Change (Change) and how one participates and leads change efforts. Once a theoretical foundation is established, LDR 3263: Leadership Experience (Experience) provides an opportunity for theory to be observed and practically applied. The capstone course, LDR 4105: Leadership and Complexity (Capstone), provides an opportunity to synthesize all material learned in previous core courses. Structured reflection is provided throughout each course using various methods such as discussions, reflective essays, journaling, and presentations. The sixth Certificate course is the student's choice from a pre-approved course list which supports their overall leadership learning. This supporting course may be in their academic discipline or of personal interest to them. This allows students to apply theories and concepts learned in core Certificate classes to other theoretical concepts.

Through the curriculum of the Certificate, there is an emphasis on values clarification and development. Mentioned specifically in the Certificate's learning outcomes is a section on Values Clarification. "Students will demonstrate the ability to clarify their personal values and discuss how their values can affect their career goals and relationships with others" (Dalton \& Beckham, 2005, p. 1). The founding documents of the Leadership Certificate detail areas of knowledge, skills, and values that students who successfully complete the Leadership Certificate will possess: (1) the individual, (2) in partnerships, (3) in groups, and (4) in community. In the individual area, self-awareness and critical thinking are cited as two sub-outcomes of the Leadership Certificate program. Students enrolled in leadership courses through the Leadership Certificate were selected because these courses provide them with a working idea of the concept of values. Through their coursework, they have been in an environment where they are encouraged to make meaning of their experiences, and reflect on themselves.

\section{Methodology}

This study was a qualitative phenomenological study of how college students clarify their values and was conducted at a large Doctoral/Research Extensive university in the southeastern United States of America. We chose a phenomenological study because we believe capturing the essence of the experience is the best way to determine the answers to the research questions (Creswell, 2007, 2008; Moustakas, 1994). For this study, two individual interviews were conducted with 15 junior-level students who were enrolled in or had successfully completed a leadership course. Prior to the first meeting, demographic information was gathered on each participant. Participants were sent an email requesting their pre-determined demographic information. In the first meeting with participants, students were asked to complete a Values Clarification activity (Simon et al., 1978) to provoke their thinking in regard to their values. After this activity, students were asked questions about values. In the second interview, their experiences clarifying their values were explored. After the interviews reached a saturation point, a point where the interviewees no longer provide new information (Ryan \& Bernard, 2004), we began data analysis using thematic coding and other phenomenological procedures.

Participants. Participants were chosen with a purposeful sample methodology (Seidman, 2006). We used purposeful sampling to capture 15 students who were enrolled in or who had successfully completed at least one leadership class. Junior-level students were chosen 
because of their developmental levels through their college experience, and their maturity to answer the questions of their values. In attempt to recruit students for the study, students enrolled in the Leadership Certificate classes were first e-mailed. When students replied to the email, they were contacted individually to determine a time to meet. We also went to the Leadership Certificate classes to ask for participants. If a student wanted to be contacted for an interview, then he or she wrote their contact information on a sheet of paper. If a student was not interested, then no contact information was listed and the student returned a blank sheet of paper. Students were asked to volunteer, so any junior-level students that were currently enrolled in a leadership class or who had completed a leadership class were eligible for the study.

Data Collection. For the data collection, we utilized a semi-structured interview format coupled with a Values Clarification activity (Simon et al., 1978). The combination of these two methods assisted in maintaining a consistent conversation with the activity and allowed the students to have a baseline for communication. Conducting the Values Clarification activity helped the participants frame their thoughts prior to the more in-depth semi-structured interview.

During the first interview, we asked them to complete a Values Clarification activity (Simon et al., 1978). We specifically utilized Strategy Number 1: Twenty Things You Love to Do and a modified version of the questions in Strategy Number 10: Values Whips in the interview process (Simon et al., 1978). Each strategy asks the participant to answer a question or series of questions.

In the second interview, each participant was asked how their leadership class (or classes) affected their clarification of personal values. Additionally, students answered questions related to their decision-making process surrounding their values and how their leadership classes affected their lives, specifically in regard to how they conceptualized their values. We asked students to define their personal set of values, and how they believe their values fit with their daily experiences as student leaders.

Throughout the interview process, it was essential to gain concrete examples of the phenomenon. "The most outstanding quality of data sought by the phenomenological researcher is concreteness, that the descriptions reflect the details of lived situations rather than hypotheses or opinions about, explanations of, interpretations of, inferences, or generalizations regarding the phenomenon" (Wertz, 2005, p. 171). In order to protect participant identities, we utilized pseudonyms. The pseudonyms were chosen at random, and do not represent racial or ethnic backgrounds. However, when choosing pseudonyms, we attempted to choose names that would typically coincide with the gender of the participant.

Data Analysis. The data analysis consisted of transcribing the collected semi-structured interviews and coordinating the Values Clarification exercises (Simon et al., 1978). Beginning with transcription, we coded the responses looking for themes, following standard qualitative data analysis procedures. Since this is a phenomenological study, we followed the guidelines Creswell (2007) suggested for data analysis in a phenomenological study.

First, we developed a list of significant statements, seeking how participants experienced the phenomenon. We took these significant statements, and looked for themes. Next, we wrote 
the textural descriptions of how the experience happened, including verbatim examples. We followed with detailing how the experience happened, the structural description. Finally, we wrote a description of the phenomenon to capture the "essence" of the experience. We were sure to include the "what" and the "how" of the experience for the participants (Creswell, 2007).

The Values Clarification activity assisted students to begin to clarify their values and begin thinking prior to the second interview session. This additionally helped in the analysis, as we were able to compare the conversations surrounding the Values Clarification activities, and have documents to analyze at a later date to assist in completing the full picture of the student experience (or phenomenon) with values clarification (Simon et al., 1978). These multiple forms of data assisted in triangulation. Additionally, we asked a colleague who was familiar with the topic to look over the raw data. Finally, we asked participants if the results we found were plausible (Merriam \& Associates, 2002) via email and telephone. This data collection and analysis led to two major themes emerging.

\section{Findings}

Through the interviews, two major themes emerged as areas where values clarification occur within leadership-focused undergraduate courses. These themes include course curriculum and structure, and leadership learning environment. Within each of these themes, more specific subthemes also emerged. We focused on these two major themes intentionally, as they connect with our research questions and the specific context of leadership courses.

Leadership courses instruct students to become more globally competent leaders, and result in their marketability in the workforce. The unique nature of the classroom environment allows for significant gains in leadership learning and behavior (Rosch \& Anthony, 2012). The reflective and experiential educational environment of leadership courses creates an opportunity for students to make meaning of their experiences, and understand their roles as leaders in the process (Guthrie \& Bertrand Jones, 2012). "Having a comprehensive leadership education program provides the knowledge and skills that students need to become nationally competitive. Students with a strong leadership learning foundation become leaders in their academic fields" (Osteen \& Coburn, 2012, p. 8).

One of the specific guiding questions for this study was "Do students clarify their values through a leadership course?" Simply stated, the leadership curriculum has helped students to clarify their values. Through the reflective and experiential nature of the classroom, participants reported clarifying their values in the context of the leadership coursework. Participants identified specific features of the leadership courses that impacted their values clarification that are included in subsequent sections: course curriculum and structure, and leadership learning environment.

Course Curriculum \& Structure. When asked if leadership courses allowed participants time to reflect on their values inside and outside of the classroom, thirteen participants indicated the leadership courses allowed them to reflect on their values. For example, Mercedés, a Family and Child Sciences major, recounted these conversations in many different aspects of her college experience. However, where she discussed the topic "a lot" was 
in her leadership classes. "We talk a lot about values and what it means to be an authentic leader and leading with strong values... definitely at school is where I've had the most actual conversation and reflection." Vera, who was double majoring in Political Science and Urban and Regional Planning, also went through each course and how it helped to clarify her values, specifically how she applied leadership theory to her values. She shared the Theory course helped her to jot down her values to see if they are congruent with the theory. "Theory helps me to put the puzzle together, it helps me to be a leader...Change was personal and depth, where leadership theory brings me back into how I can make it more successful in my organization. That's what theory does for me."

In her interview, Mercedés also shared how her coursework explored her values differently. She mentioned the progression of the courses and how she reflected on her values. She said the Theory course explored what it means to be a well-rounded leader. In these courses, she read a lot of other people's thoughts on what they value. Through reading about other people's values, Mercedés began to think individually about what values she holds. In the Groups course, group dynamics are explored. "We talk about values again and how values of a group...create the experience for you...it's more of a simulation than actual life experience." In this experiential learning opportunity, Mercedés was told what to do to be a good group member, and then she acted it out. In the Change course, there was a lot of discussion. There was "a little bit of talking about what other people value, but more talking about how as an individual and in your individual situation, you can use your values and articulate them or whatever it is, for whatever change you're inspiring." Mercedés' experience is that in Change, she talked more about her own experience, where in her other two classes, the coursework was more focused on the values of others.

Seven students indicated the Change course allowed them to reflect on their values. Seven individuals also cited the Groups class as providing the opportunity for reflection, while one mentioned the Leadership Experience course. Nine participants shared the Theory course allowed them to reflect on their values.

Course assignments. Participants shared various experiences when asked what specific assignments and/or activities in the Leadership courses contributed to reflecting on their values. Participants often shared more than one assignment or activity as being influential in their values clarification. Class discussions were the most commonly cited experience in the Leadership courses that allowed students to think about their values. Of the 12 responses, six respondents cited the Change course, and three each cited the Theory and Groups courses. For example, Ryan, an International Affairs major, noted the "constant application questions" as an area where he reflected on what was important to him, how to lead, and how to handle situations that came his way. Six people shared the importance of readings (four referenced Theory, while one each referenced Change and Groups). For Jamie, who was a Statistics major, the section of the text from the Groups class has facilitated her reflection on her values. Specifically, she discussed the list of values at the end of the text. One activity Jamie mentioned was the leadership challenge with the five pillars of leadership. In this activity, Jamie explains, "one of them is clarify your values, so obviously it's a core part of leadership." 
Five students referenced the Personal Change Paper in Change as an opportunity to reflect on their values. For example, Mercedés shared the personal change story assignment was the most influential work for her in the leadership coursework. Through this assignment, she reflected on her values.

I don't necessarily know if this is the way it was for other people but because mine was kind of a change of personality, or more of an awareness of things that I value that maybe I shouldn't. Because it was so reflective, I was able to see how values played into things that I wrote about.

Vera also mentioned the Personal Change paper. She shared that she had to "travel through what has happened to you, where are you now, and how has that affected you... what do you want to change?"

Four students shared the Values Self-Portrait from the Groups class as a way to clarify and reflect on values. When specifically asked what experiences from her leadership courses helped her to identify her values, Susan, who was a Family and Child Sciences major, first cited her values self-portrait. The assignment was for Susan to articulate her values in a video format. At first, I kind of thought to myself how do I sum up how I feel in words, like single words? I really hated that. But then I got to thinking; because everyone was like love, hope... So asking me to do that made me think and when I thought it was things that I think had been challenged or had hurt my feelings and that made me feel like more strongly about those things. So I think how I identified them, one was being asked to identify them. Made a big difference.

Three participants cited the "Trash Your Values" activity in the Change course, which focuses on choosing which values are most important to them. Three participants also noted the Change Prospectus from the Change course as a time to reflect on their values. Ryan discussed how the final projects (including the Change Prospectus) encompassed all he learned through the semester, including how his values influenced his leadership. He said the final papers were "key." Also from the Change class, two students noted the importance of class presentations. From the Groups course, two students shared that engaging in community service allowed them to reflect on their values, while two people noted the Mentor paper in Theory.

Additionally, there were some responses only one participant noted as helpful in his or her clarification of values. These assignments were as follows: leading class sessions, reflection, the interview with a mentor assignment, the leadership philosophy paper, the peer interview, and reading summaries.

Leadership Learning Environment. While the specific course curriculum was important in values clarification in the Certificate, there were other specific experiences cited by the participants, which pointed to the overall environment for learning in the leadership courses. These included the quality of the faculty, class size, and the multidisciplinary students enrolled in the courses.

Quality of the faculty. The quality of the faculty was important to values clarification for the participants. Ryan expressed that he enjoyed and appreciated the one-on-one 
relationships with his instructors in the Leadership Certificate. He mentioned his instructors were concerned about him as a person, inside and outside of class. Ryan said the teachers seemed to "really enjoy" their jobs. "The leadership classes have really changed my view on what it is to be an educator and what you can learn from it...they seem very passionate. That is something that has really altered my view on learning." Michael said the Leadershipinstructors value the relationships of the individual student more so than his other professors. Susan agreed and shared the instructors and the care they provide to the students in the Certificate are essential. She said,

The teachers are really invested and they really care. And it's not like it's a class where you grade 700 scantrons. It's a class where you hear what we say and you see how we interpret this reading and how we can apply it and I think, too, like you guys are really able to help us see it in our lives...

Instructors also helped students to think about their values. In Change, Vera's instructor would encourage the students to think a bit deeper: "How is this congruent with your value set?" "What was that sparking moment for you?" The discussions were meaningful to her, and she enjoyed exploring the deeper meanings through conversations.

Class size. Participants also discussed the class size as important to their values clarification. Susan believed the smaller class size and the ability to have one-on-one conversations added to her learning. Through the small groups in the leadership classes, Susan made connections. She said the people in her group still call each other, and continue to hang out even though they are no longer in class together. Both Michael and Ryan specifically mention the smaller class size as influential on their clarification of values.

Multidisciplinary students enrolled. In addition to smaller classes, participants shared the multidisciplinary makeup of the courses as beneficial to their values clarification. Susan shared that the students in the courses are what make them special. She says the "right people" are in the courses. Susan explains her fellow students, "it just seems like they're there for the right reasons."

Vanessa, who was double majoring in International Affairs and Psychology, shared a similar sentiment; there were the right people in the room to have values conversations. She explained it was not always an explicit conversation in values during class, "but more organically, like okay, my take on this specific thing that we're talking about is this because it relates to something that I value." Mercedés shared a similar thought. For her, it was notalways explicit in the conversation, but it was often implicit during the class discussions. "It's not even necessarily explicitly values but ways as a leader, things that you should adopt or ways that you should communicate or personality traits you should try to adopt which in the end are values..." Vanessa shared that once she learned how to articulate and understand her values (and how they are applied), she thinks it comes up in conversation naturally.

I'm not specifically talking about my values. I'm talking about something that's related to them. So I think when you talk about things in class, I feel like that has to be related to your values in some way because I'm not going to say something that's completely just off base. 
Cathy, who was double majoring in Political Science and Interdisciplinary Social Sciences, cited the environment of the leadership classes as one of the reasons the courses helped to clarify her values. Specifically, it was an environment where students discussed values frequently. "It was a place to be open and not, in most cases, ashamed or feel like you were bragging about achievements and accomplishments because it was a constant environment for how do you make this better?" Cathy and her classmates would ask each other for help. When they were stuck, they would bring the situation to class, and ask colleagues. They would also ask for personal advice as well, such as "I'm stuck between two leadership positions. Can I do both? Should I do one? Should I do none? What do you think? What do you think... knowing that you understand values." This supportive, values-based classroom was critical to Cathy's growth. She likens the environment to fertilizer. "It's like Miracle Gro...for student organizations, for student development. Just having, I'd say similar minded but differently oriented group of students that can challenge each other and support each other through different processes." For Cathy, had it not been for her leadership courses, she would have had little conversation about her values. Outside of her leadership classes, she only knows two people who talk about values, her "overdramatic boyfriend," and an "overcritical, über religious friend."

I firmly believe that had I not taken the courses, that I would not have constantly been thinking about my values because ... before, we have all these beautiful grand thoughts and plans about what university is going to be and had I not had that constant check... I think so much it framed my understanding of [college] as something that's service minded, a place that's service minded. And a place that, that students are not incubated, but supported to a state of constant challenge, constant leadership ... I felt like I differed from other students because I had had that exposure but I felt that I was back in that ideal environment when in those classes.

Susan shared she values the diversity in the leadership courses. She believed that through this diversity, she has been able to learn and grow, especially when it comes to her value set.

I think I've learned just in life but especially in our leadership classes is that the diversity in opinions and perspectives creates a better final product... our communities now are so diverse. There's not one homogeneous culture or community or anything anymore. And we still have very... flat lined ideals and ideas and it's hard for people to break away from that but when you throw like a little salt and a little pepper, like it just makes it better and easier to get and understand.

For Ryan, the students in the leadership classes, "knew and respected each other's values, it was an unspoken understanding of your values." He said through the coursework, students were able to deliberately articulate what they believed, and what others in the class believe. He said the students feed off of each other, because they have close relationships where they have articulated their values. This allowed for constructive discourse around values, and students challenging each other's values. The students respected each other's differences, and did not want to offend each other. Through the Change course specifically, students shared many personal stories, so it was important to Ryan that the environment of respect was created. He said during the discussions, he learned a lot. Ryan would take what happened in one person's organization, and apply it to his. There were different perspectives around the room, which Ryan was thankful for. He would listen to his classmates, and try to think about his values differently. "I think you take from what they said, because they may have said something really insightful. 
And you take it back to your organization, and you try to implement it. Or you just think about it, and it changes who you are, or it changes your view." He summarized his experience, sharing that with so many different people in the leadership classes, he was exposed to many different ways of thinking (which he had not been before). This exposure allowed him to examine and then clarify his values.

\section{Implications and Recommendations}

This study is important for developing opportunities for leadership learning in higher education. It affirms the importance of values clarification in leadership education, both in a curricular and co-curricular format. Through the study, students cited both curricular mechanisms (papers, discussion, courses, etc.) and co-curricular mechanisms (break ups, roommate challenges, role models, clubs and organizations) as venues for their values clarification. However, the leadership courses were a place where students made meaning of their experiences. They were able to apply their out-of-class experiences and articulate what they learned through the leadership curriculum. The curriculum allowed students to reflect on their values in different ways, that without the classes, we are not sure participants would have been able to state their values as clearly.

The structure of the learning in the leadership courses was influential for participants. The curriculum outlines what the students will learn, and creates a contract between the instructor and the student. The coursework affords students the opportunity to apply what they have learned outside of the classroom inside the classroom. The curriculum allows an opportunity to conduct targeted activities and assignments that focus on values. The students in our study learned about their values clarification through the discussions and reflections. It was important to the participants to be able to take the time to talk in class, and then take time away to think about what they value. Overall, the leadership courses allowed students to think about and process with others about their values in a variety of ways. It is important for educators to take advantage of benefits and learning provided by this structure.

The implications for importance of implementing particular assignments that are beneficial in clarifying values, was a key highlight of our findings. It is important to continue to have values integrated into the learning outcomes or curriculum of leadership education. Valuesbased assignments and activities facilitate the clarification of values. Engaging in these activities and experiences will assist students in values clarification. Utilizing assignments such as the consistent weekly application questions allowed leadership instructors to encourage participants to apply what they were learning in the classroom to their out of classroom lives. This practical application of leadership concepts was impactful and a clear option for intentional growth of values understanding for students in future classrooms. In addition, there were specific papers and other assignments that were beneficial, such as the personal change paper and the change prospectus. The values portrait, where students had to choose three values and then discuss them was another assignment that impacted their values clarification. Susan shares,

I just got out of groups and communities... we had to do our values self-portrait and we did it at the beginning... so the whole class, we kind of tied everything to our values and we just had our last class Thursday and... every question was, so how does this relate to your values? Values, values, values... I think at the end, it made us more thankful 
because not only could we apply our class to real life but I think we realized values that we said we had that we didn't have or that we didn't have that we thought we had. The inclusion of assignments such as papers or a more non-traditional, creative assessments creates the expectation in the course for students to have a structured outlet to formally review and express their values.

It was not only the assignments that students shared as helpful in their values clarification process, but also the classroom environment. Participants cited the smaller class sizes of the Leadership Certificate as beneficial. Through the smaller class sizes, students were able to get to know each other, and know what they value. This afforded them the opportunity to have conversations with their peers surrounding values. Students in the courses come from different academic disciplines and varied organizations, but overall they had a shared value of wanting to lead. This shared value set allowed the classroom to become a laboratory for students to explore their values with people who may be different from themselves. The classroom size of the courses in the Leadership Certificate are generally no larger than 25 students (with the exception of the online Leadership Theory course). This purposeful number cap is intended to create a classroom environment for students to establish relationships which allow for conversations of values, recognition of difference, and reflection on their own perspectives.

The faculty's investment in the individual student went a long way in the values clarification for participants. Ryan shares that he enjoyed the relationship with his leadership instructors and their investment in him was something he valued. These faculty relationships were similar to the relationships between students and their role models, each being influential on their values development. A key element in this study is to recognize the importance of the leadership course instructor in the students' experience.

In developing communities of learning, leadership educators should consider the size of the class or the group. Smaller class sizes encourage conversation, reflection, application, and interpersonal interactions. Keeping a class limited in size allows time for each student to participate and to share their values with others. In the smaller groups, students are able to listen to their peers and form relationships with their classmates. This close-knit environment aids in the clarification of values. In order to create a close-knit environment, a leadership educator must be dedicated to the students with whom he or she works. This study demonstrates that role models have an impact on values clarification. For students in the leadership courses, instructors become those role models. In campus engagement activities, advisors become that role model. Leadership educators can become these role models through the smaller groups and a dedication to the students.

\section{Conclusions}

Mercedés shared "I think college really brings the ideas of values-based decision-making to the forefront...the thing that I think is different about college is there's some niche for somebody and in every niche, I've found there's some kind of values conversation." For each participant in the study, they were able to name their values when asked. The leadership courses were areas where participants specifically named as aiding them in their values clarification. Students shared there were specific courses that were beneficial to learning about their values, 
and within those courses, there were specific assignments that assisted them in clarifying their values. The instructors in the leadership courses were cited as reasons students clarified their values. Additionally, participants believed the course size and the students enrolled in the courses were essential to their values clarification learning. The opportunity to apply what they were learning in the classroom to their lives and allowing time for reflection on their values was critical for some participants.

Learning to identify and clarify values in the context of the Leadership Certificate was useful for the participants in this study. By thinking about her values, Vanessa shared it is a purpose, a means to an end. She felt it was important to know her values to be able to create a path for her in college. By knowing her values, she knows the path she wants to take. Including values clarification as an integral part of leadership courses is essential, not only in character development, but developing leadership capacity in our students for them to be the ethical leaders we need for today and the future.

\section{References}

Attarian, A. (1996, October). Integrating values clarification into outdoor adventure programs and activities [Electronic version]. Journal of Physical Education, Recreation and Dance, $67(8), 41-44$.

Boone, T. (2003, June). Values clarification in exercise physiology. Professionalization of Exercise Physiology, 6(6), 1-5. Retrieved May 26, 2011.

Connaughton, S. L., Lawrence, F. L., \& Ruben, B. D. (2003, September/October). Leadership development as a systematic and multidisciplinary enterprise [Electronic version]. Journal of Education for Business, 46-51.

Cress, C. M., Astin, H. S., Zimmerman-Oster, K., \& Burkhardt, J. C. (2001). Developmental outcomes of college students' involvement in leadership activities. Journal of College Student Development, 42(1), 15-27.

Creswell, J. W. (2007). Qualitative inquiry \& research design: Choosing among five approaches (2nd ed.). Thousand Oaks, CA: Sage Publications.

Creswell, J. W. (2008). Educational research: Planning, conducting, and evaluating quantitative and qualitative research (3rd ed.). Upper Saddle River, NJ: Pearson Education, Inc.

Dalton, J. C., \& Beckham, J. (2005, April 25). Proposal: Certificate in Leadership Studies. [Proposal made in Tallahassee, FL]. Copy in possession of author.

Ethics Resource Center. (2009, May 29). Definitions of values. Retrieved February 21, 2015, from www.ethics.org/resource/definitions-values 
Evans, N. J., Forney, D. S., Guido, F. M., Patton, L. D., \& Renn, K. A. (2010). Student development in college: Theory, research, and practice (2nd ed.). San Francisco, CA: Jossey-Bass.

Guthrie, K. L. \& Bertrand Jones, T. (2012). Teaching and learning: Using experiential learning and reflection for leadership education. In K.L. Guthrie \& L. Osteen (Eds.), Developing students’ leadership capacity (pp. 37-52). San Francisco, CA: Jossey-Bass.

Guthrie, K. L., \& Bovio, B. (2014, February). Undergraduate Certificate in Leadership Studies: An opportunity for seamless learning. Journal of College \& Character, 15(1), 25-31.

Guthrie, K. L., \& Thompson, S. (2010). Creating meaningful environments for leadership education. Journal of Leadership Education, 9(2), 50 - 57.

Kirschenbaum, H. (1976). Clarifying values clarification: Some theoretical issues and a review of research [Electronic version]. Group \& Organizational Management, 1(1), 99-116. doi:10.1177/105960117600100109

Kirschenbaum, H. (2000). From values clarification to character education: A personal journey [Electronic version]. Journal of Humanistic Counseling, Education and Development, 39(1), 4-20.

Kirschenbaum, H., Harmin, M., Howe, L., \& Simon, S. B. (1977, June). In defense of values clarification [Electronic version]. The Phi Delta Kappan, 58(10), 743-746.

Komives, S. R., Longerbeam, S. D., Owen, J. E., Mainella, F. C., \& Osteen, L. (2006). A leadership identity development model: Applications from a grounded theory. Journal of College Student Development, 47(4), 401-418.

Merriam, S. B. \& Associates (2002). Qualitative research in practice: Examples for discussion and analysis. San Francisco, CA: Jossey-Bass.

Mosconi, J., \& Emmett, J. (2003, December). Effects of a values clarification curriculum on high school students' definitions of success [Electronic version]. Professional School Counseling, 7(2), 68-78.

Moustakas, C. E. (1994). Phenomenological research methods. Thousand Oaks, CA: Sage Publications.

Northouse, P. G. (2010). Leadership: Theory and practice (5th ed.). Thousand Oaks, CA: Sage Publications.

Osteen, L. \& Coburn, M.B. (2012). Considering context: Developing students' leadership capacity. In K.L. Guthrie \& L. Osteen (Eds.), Developing students' leadership capacity (pp. 5-16). San Francisco, CA: Jossey-Bass. 
Purpel, D. E. (1991, May-June). Moral education: An idea whose time has gone. The Clearing House, 64(5), 309-312.

Ryan, G. W., \& Bernard, H. R. (2004). Techniques to identify themes in qualitative data. Retrieved October 26, 2011, from http://www.analytictech.com/mb870/Readings/ryanbernard_techniques_to_identify_themes_in.htm

Schwartz, A. J. (2015). Inspiring and equipping students to be ethical leaders. New Directions for Student Leadership, (146), 5-16. doi:10.1002/yd.20131

Schwartz, S. H. (1994). Are there universal aspects in the structure and contents of human values? The Journal of Social Issues, 50(4), 19.

Schwartz, S. H., \& Bilsky, W. (1987, September). Toward a universal psychological structure of human values. Journal of Personality and Social Psychology, 53(3), 550-562. doi:10.1037/0022-3514.53.3.550

Seidman, I. (2006). Interviewing as qualitative research (3rd ed.). New York, NY: Teachers College Press.

Simon, S. B., \& deSherbinin, P. (1975, June). Values clarification: It can start gently and grow deep [Electronic version]. The Phi Delta Kappan, 56(10), 679-683.

Simon, S. B., Howe, L. W., \& Kirschenbaum, H. (1978). Values clarification: A handbook of practical strategies for teachers and students (2nd ed.). New York, NY: Hart Publishing Company, Inc.

Smith, B. H. (2013). School-based character education in the United States. Childhood Education, 89(6), 350.

Thompson, D. L. (1991). Introduction: Academe - the institutions and individuals: An introduction to a discussion of morals in higher education. In D. L. Thompson (Ed.), Moral values and higher education: A notion at risk (pp. 1-10). Albany, NY: State University of New York Press.

Wertz, F. J. (2005). Phenomenological research methods for counseling psychology [Electronic version]. Journal of Counseling Psychology, 52(2), 167-177. doi:10.1037/00220167.52.2.167

\section{Author Biographies}

Mackenzie R. Fritz serves as Associate Director for Academic Initiatives, Student Behavior and Leadership in Residence Education and Housing Services at Michigan State University. Her Ph.D. is in Higher Education Administration from Florida State University. Her 
research interests include leadership, character development, and the residential experience. Mackenzie can be reached at: mfritz@rhs.msu.edu.

Kathy L. Guthrie is Associate Professor in Higher Education at Florida State University. She serves as Director of the Leadership Learning Research Center and Coordinator of the Undergraduate Certificate in Leadership Studies. Kathy is the Associate Editor for the New Directions in Student Leadership series. She can be reached at kguthrie@fsu.edu. 